\title{
Vertically transmitted infections and extrauterine growth restriction in preterm neonates: a new risk factor
}

\author{
Verônica Cheles Vieira 1 \\ (iD) https://orcid.org/0000-0001-6395-4096 \\ Raquel Cristina Gomes Lima 2 \\ (iD https://orcid.org/0000-0001-5344-3508 \\ Daiane Borges Queiroz 3 \\ iD https://orcid.org/0000-0003-0665-1114 \\ Danielle Souto de Medeiros 4 \\ iD https://orcid.org/0000-0002-2480-8990
}

1,3,4 Instituto Multidisciplinar em Saúde. Universidade Federal da Bahia. Rua Hormindo Barros, 58. Candeias. Vitória da Conquista, BA, Brasil. CEP: $45.029-094$.
E-mail: veronicacheles@gmail.com
2 Departamento de Ciências Naturais. Universidade Estadual do Sudoeste da Bahia. Vitória da Conquista, BA, Brasil.

\begin{abstract}
Objectives: to investigate the association between Vertically Transmitted Infections (VTI) and Extrauterine Growth Restriction (EUGR) among premature infants in Neonatal Intensive Care Units (NICU).

Methods: part of a large non-concurrent cohort study with medical records analysis. We evaluated EUGR in premature infants at a gestational age at birth of $\geq 32$ weeks and $<36$ weeks and presented a corrected gestational age of 36 completed weeks during a 27-day birth follow-up. Premature infants with major congenital anomalies were excluded. We analyzed associations among EUGR, VTI and covariables related to maternal disease, birth characteristics, perinatal morbidities and clinical practices.

Results: out of the 91 premature infants, 59.3\% (C195\%=48.9-69.0\%) developed EUGR. $V T I$ were observed in $4.4 \%$ of the population; all premature infants affected by VTI had EUGR. The VTI found were syphilis, cytomegalovirus disease and toxoplasmosis. The final analysis has showed a positive association between VTI and EUGR $(R R=1.57$; CI95\%=1.072.30); the female covariables $(R R=1.50 ; C 195 \%=1.11-2.02)$, moderate premature classification $(R R=1.41 ; C 195 \%=1.06-1.87)$ and small for gestational age $(R R=2.69 ; C 195 \% 1.85$ 3.90) have also influenced this outcome.

Conclusion: this study revealed VTI as an important morbidity factor, with impact on the increased risk of EUGR between premature infants affected by these diseases.
\end{abstract}

Key words Premature infant, Growth, Malnutrition, Vertical transmission 


\section{Introduction}

Growth evaluation and surveillance are essential for a good monitoring of preterm neonates. Being a preterm should be considered as a condition that predisposes the neonate to nutritional risk due to several limitations resulting from preterm birth, such as incomplete development of organic systems and the presence of several comorbidities, especially those related to digestion and absorption of nutrients. 1

Several services have observed the universal occurrence of growth restrictions after birth and a higher incidence in the group of preterm neonates, 2,3 and for this morbidity the term, Extrauterine Growth Restriction (EUGR) was defined. EUGR is a marker of severe nutritional deficit in the first weeks of life, and can be diagnosed at 36 or 40 weeks of corrected gestational age (CGA) based on intrauterine or postnatal growth reference curves. ${ }^{4}$

Complications resulting from EUGR in the initial period of life can result in permanent alterations for the child, decreasing central nervous system development, cognition, and somatic growth. 5 In addition, these complications can persist even in adulthood, promoting the onset of several chronic diseases such as coronary artery disease, type 2 diabetes mellitus, cancer, osteoporosis, and a variety of psychiatric diseases. 6

Some authors reported that several factors can determine the impact growth in the postnatal period, interacting in a complex way for the occurrence of EUGR. They include genetic and environmental factors such as inadequate nutrition during the fetal and neonatal period, hospitalizations, drug treatments, endocrine abnormalities, and morbidities related to prematurity itself. $4,7,8,9$ Other conditions can also influence the occurrence of EUGR in preterm newborns, such as "small for gestational age" (SGA) classification, low birth weight, and the need for resuscitation at birth. 7,10

However, there are still some gaps in the studies, mainly related to factors possibly associated with EUGR that have not been investigated yet. In Brazil, some infectious conditions are still prevalent in the population, which acquire greater relevance when affecting pregnant women and represent risks for the fetus and newborns, 11 especially in case of preterm. According to Madrid et al.,12 vertically transmitted infections (VTI) significantly influence neonatal and infant morbidity and mortality rates and can cause severe consequences for the newborn, contributing with the occurrence of congenital malformations, tissue injuries, and death due to prematurity and low weight at birth. The transmission of these infections occurs more frequently through the placenta, after the mother is infected, or through direct transmission through the cervix during pregnancy. There are several infectious causes related to these diseases, such as cytomegalovirus, Toxoplasma gondii, syphilis, herpes, hepatitis B and C, HIV, HTLV, and others being documented in the literature. 13

In Brazil, prenatal screening for these diseases has been performed as an early detection and damage reduction strategy, considering that VTI are public health problems that severely impact maternal and infant health. ${ }^{14}$ A study conducted by São Pedro et al. 15 in the state of Bahia evaluated 64,743 pregnant women that were tested and observed a higher prevalence of syphilis and toxoplasmosis in the Southwest and South macro regions of the state.

Considering this scenario, this study raised the hypothesis that VTI may also interfere with the growth of preterm children. Thus, this manuscript aimed to investigate the association between VTI and EUGR in preterm infants admitted to Neonatal Intensive Care Units (NICU) in the Southwest of Bahia.

\section{Methods}

This research was derived from a non-concurrent hospital-based cohort study called Coorte Nascer Prematuro (Preterm Born Cohort), with documentary analysis of the medical records of preterm newborns admitted to the NICU at three hospitals in a city in the Northeast of Brazil from January 1, 2016 to December 31, 2017.

The study was conducted in a medium-sized city that provides NICU services in three units, which use standardized clinical and nutritional practices and similar clinical protocols and have equal adherence levels.

The data were collected from the medical records of hospitalized preterm infants and stored in the Medical Archives and Statistics Service at the hospitals, using a specific questionnaire from Nascer para o Brasil (Born for Brazil) survey. Data collection was performed by voluntary trained health researchers under the supervision of neonatologists. 16 A pilot study was conducted in May 2018 to improve the instrument, standardize and to test field logistics, which included about $20 \%$ of the total number of medical records from the three NICU between November to December 2015. Data collection was conducted from June 2018 to May 2019 using tablets containing a digital questionnaire generated by Kobo Toolbox 1.4.8 ${ }^{\circledR}$ application. 
This part of the collection included a group of preterm infants with gestational age (GA) at birth $\geq$ 32 and $<36$ weeks, presenting a CGA of 36 complete weeks within the 27-day follow-up period, and hospitalized at the neonatal unit.

Newborns with major congenital anomalies were excluded from the study (severe anatomical changes such as complex congenital heart defects, gastrointestinal tract atresia, abdominal wall defects, hydrocephalus, encephalocele, and diaphragmatic hernia). The dependent variable used in the study was EUGR in preterm infants at CGA of 36 weeks, being dichotomized as no or yes. To identify the newborns with EUGR, the weight at CGA of 36 weeks was compared, considering as preterm infants the ones who had a weight $\mathrm{z}$ score $\leq-2$ by specific growth curves for preterm infants. 17

The main independent variable studied was VTI (no or yes), characterized by the occurrence of at least one type of VTI (toxoplasmosis, rubella, syphilis, cytomegalovirus, herpes, HIV).

The covariables for adjustment were related to the following blocks: hypertensive disease during pregnancy, birth characteristics, neonatal morbidities, and clinical practices.

The qualitative variable related to the presence of hypertensive disease during pregnancy (preeclampsia, eclampsia, hypertensive disorder of pregnancy, HELLP syndrome) was dichotomized in no or yes.

The birth characteristics analyzed were: sex (male, female); birth weight (in grams), categorized as greater than $1500 \mathrm{~g}$ or less than $1500 \mathrm{~g}$; and GA, classified as late preterm (between 34 weeks and 36 weeks and six days) or moderate preterm (from 32 weeks to 33 weeks and six days). 18 GA was defined by the obstetric estimate, preferably using the date of the last menstruation, followed by ultrasound, and finally the GA estimated by the New Ballard and/or the Capurro method. Neonates with a birth weight $\mathrm{z}$ score less than $-1.29(10 \%$ percentile $)$ were defined as SGA (No or Yes) ${ }^{19}$ according to the Intergrowth21 curves. The variable intrauterine growth restriction was categorically created and evaluated as no or yes.

The neonatal morbidities (evaluated as no or yes) correspond to the following diseases: early sepsis, late sepsis, and respiratory distress syndrome.

Clinical practices were evaluated by the variables need for resuscitation procedures in the delivery room, use of oxygen at 36 weeks, number of days without enteral feeding, and time of supplemental oxygen use (in days). The last two variables were numerical, and the others were categorical (no or yes).

Descriptive analyses were performed by using frequency measurements for categorical variables, and medians, and minimum and maximum values for numerical variables. Normality tests were performed for continuous numerical variables (graphical analysis, Shapiro-Wilk, mean and median evaluation, and among others), all presenting non-parametric distribution.

The Poisson regression with robust variance was used for bivariate analysis between categorical variables and outcomes, and the Wald test was used to estimate the $p$ value. The medians of the quantitative variables were compared using the Mann-WhitneyWilcoxon test. The relative risks (RR) for the occurrence of EUGR and their respective $95 \%$ confidence intervals (CI95\%) were also estimated.

The Stepwise Backward method was used for multivariate analysis with the inclusion of explanatory variables associated with the outcome at a significance level below $20 \%$ in bivariate analysis. A significance level of less than $5 \%$ was used for the permanence of the variables in the final model. The models were compared using the Akaike criterion, and the adequacy was evaluated by the chi-square test. The Stata statistical software version 15.0 (Stata Corporation, College Station, USA) was used for data coding and statistical analysis.

The research was approved by the Research Ethics Committee of the Multidisciplinary Health Institute, Anísio Teixeira Campus, Universidade Federal da Bahia, on February 5, 2018, under CAAE number: 79450717.4.0000.5556.

\section{Results}

A total of 592 medical records of preterm infants were surveyed, of which 37 were excluded due to major malformations. Of the 555 eligible medical records, 155 were not found, leaving 400 preterm infants for the final sample. Of these, 91 medical records of preterm infants at CGA of 36 weeks remained in the study, since 40 preterm infants with GA at birth $\geq 36$ weeks (or 252 days of life), 182 did not reach a CGA of 36 weeks during hospitalization (born with $\mathrm{GA}<32$ weeks and one day, or 225 days), 84 were discharged, and three died before the CGA of 36 weeks were excluded (Figure 1).

Of the 91 preterm infants, $59.3 \%(\mathrm{CI} 95 \%=48.9$ - 69.0\%) developed EUGR (Figure 2). All preterm infants with VTI had EUGR. VTI was observed in $4.4 \%$ of the population (Table 1). Of those infected, Syphilis was the most frequent disease, followed by cytomegalovirus and toxoplasmosis. 
More than half of the newborns evaluated were males $(55.0 \%)$, and $23.1 \%$ had birth weight below $1,500 \mathrm{~g}$. GA at birth ranged from $326 / 7$ to $35 \mathrm{weeks}^{5 / 7}$, with $68.1 \%$ late and $31.9 \%$ moderate preterm infants. The SGA classification included $44.0 \%$, $15.3 \%$ had intrauterine restricted growth, and $29.7 \%$ were babies of mothers who had hypertensive disease during pregnancy. Resuscitation in the delivery room was necessary for $40.7 \%$ of the preterm infants, and $5.3 \%$ were using oxygen at 36 weeks of corrected age. Of the neonatal morbidities, early sepsis was present in $56.0 \%$, late sepsis in $18.7 \%$, and respiratory distress syndrome in $22.0 \%$ (Table 1).

Bivariate analysis showed a higher incidence of EUGR in preterm females $(70.7 \%)$, with birth weight below $1,500 \mathrm{~g}(90.5 \%)$, classified as moderate preterm $(75.9 \%)$ and SGA $(92.5 \%)$, who had intrauterine restricted growth $(92.3 \%)$, and whose mothers developed hypertensive disease during pregnancy $(77.8 \%)$ (Table 1$)$.

Multiple analysis showed that VTI significantly increased the risk of EUGR $(\mathrm{RR}=1.57, \mathrm{CI} 95 \%=$ $1.07-2.30)$ in preterm infants. Females $(R R=1.50$, $\mathrm{CI} 95 \%=1.11-2.02)$, and classified as moderate preterm $(\mathrm{RR}=1.41, \mathrm{CI} 95 \%=1.06-1.87)$ and SGA $(\mathrm{RR}=2.69, \mathrm{CI} 95 \%=1.85-3.90)$ were also positively associated with the outcome in the final model (Table 1).

\section{Discussion}

This study showed a high incidence of EUGR in preterm infants admitted to NICU. VTI, which are preventable by quality pre-conceptual and/or prenatal care in most cases, increased the risk of EUGR by $57 \%$, even after adjusted for the sex covariates, GA classification, and SGA.

Although EUGR is considered a universal occurrence in neonatal units, its frequency presents many variations. ${ }^{3}$ A national Brazilian cross-sectional study conducted in a NICU in 2010 showed a $29.3 \%$ prevalence of restriction in preterm infants at CGA of 36 weeks. 9 Renau et al. 20 analyzed a group of 126 preterm infants using a fetal growth curve as a parameter and reported an EUGR prevalence of $66.0 \%$. However, when evaluating only extremely preterm infants with the same GA in Canada, Shah et al.21 found an EUGR frequency of $87.8 \%$. The present study found an incidence of $59.3 \%$.

These differences can be explained by the use of different growth evaluation curves in the studies. This study used Intergrowth-21 curves as a reference for this population, as recommended by the Brazilian
Pediatric Society and the World Health Organization. They were chosen for being prescriptive and longitudinal, thus suitable to evaluate preterm infants, especially in the moderate and late groups. EUGR evaluation using Intergrowth-21 curves decreased the risk of overdiagnosis, which can occur with fetal growth curves. Currently, the dynamics of fetal growth differs from the dynamics of preterm growth, since weight gains inside and outside the uterus are influenced by different biological processes, and nutritional and environmental restrictions. Weight gain in fetuses is greater than in preterm infants, thus, the comparison of preterm infants using fetal curves will possibly increase the frequency of EUGR. Thus, fetuses and preterm infants are in different groups, therefore requiring the use of more specific curves. 22

Villar et al.22 highlighted the importance of EUGR overestimation, which can affect preterm infants. Large nutritional increases to correct an overestimated EUGR can lead to body structure composition imbalances in preterm infants and increase body fat proportion, possibly increasing the incidence of cardiovascular diseases later in adulthood. 22

Among the studies no methodological uniformity were presented. The occurrence of EUGR is investigated at different moments, either at discharge or with a CGA of 36 or 40 weeks. The evaluation of restriction at hospital discharge includes different CGA, explaining the lower restriction frequencies. Lima et al. 7 conducted a longitudinal study between 2007 and 2011 in four neonatal units of the Perinatal Care System (Rio de Janeiro) and reported an EUGR frequency of $26 \%$ at hospital discharge. Clark et $a l .23$ used data from 124 NICU to review information on 24,371 infants, identifying an EUGR incidence of $28 \%$. The present study presented higher values because the evaluation was conducted with preterm infants at CGA of 36 weeks, who were still hospitalized in the NICU, and still had morbidities associated with prematurity, thus undergoing a more effective interference of these factors in growth.

The evaluation of restriction in groups with different GA could also explain the different results between studies. Younger preterm infants present higher EUGR incidence. 8 GA estimates were also different, contributing to the occurrence of disagreements between EUGR studies, in addition to the different practices used in each service, including nutritional practices. 2,22

Authors state that EUGR occurs due to multiple causes, some of which not yet elucidated.4,24 In this context, VTI raised concerns about the interference 


\section{Figure 1}

Flow diagram: medical records analyzed in the research.

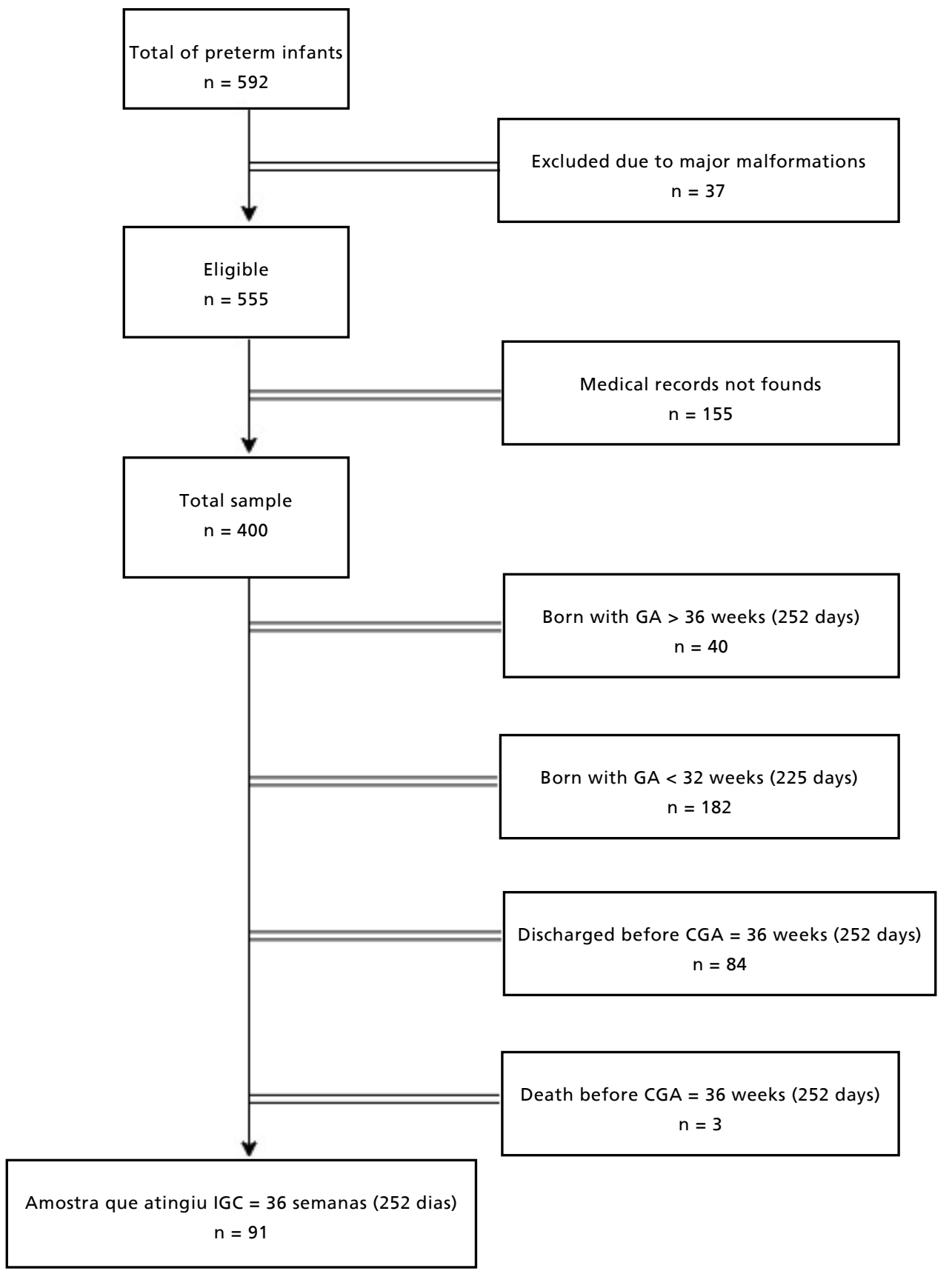

of this condition in the growth of preterm children, since they are described as important causes of fetal mortality and perinatal morbidity and mortality. 11

The higher risk of EUGR in preterm infants with VTI may be related to the worse health conditions of these newborns. Waldorf et al.13 state that the pres- ence of maternal infection caused by bacteria, viruses, and parasites can cause fetal death, multiple organ damage, or limiting sequelae. 13 When transmitted to the fetus, these infections result in the onset of systemic inflammatory responses whose damages can extend to the postnatal period. 
Inflammatory processes increase the production of cytokines such as IL6, IL8, TNF- $\alpha$, which can cause brain, gastrointestinal, ophthalmic, and lung disorders. In addition, the prevalence of infections can increase the occurrence of chorioamnionitis, being frequently associated with preterm birth. The presence of these infections during pregnancy also impairs placental development and, consequently, adequate fetal growth. 13,25

Intrauterine infections also contribute to the birth of neonates with severe clinical conditions, with a greater risk of developing bronchopulmonary dysplasia, peri-intraventricular hemorrhage and necrotizing enterocolitis. 13,25

Thus, potential VTI-related injuries that affect fetuses and neonates can explain the results of this study regarding the occurrence of EUGR in all preterm infants affected by these infections.

Health services still face challenges and obstacles to reduce the occurrence of VTI. In this context, syphilis stands out as an important public health problem, 26 being the most common VTI in this study. Regardless of the emergence of public policies to decrease the disease incidence, there is a worldwide worsening of syphilis epidemic, with a significant increase of the acquired form of the disease and a consequent increase in congenital syphilis. ${ }^{27}$ In 2013, the national mean was 3.3 cases per 1,000 births. Thus, children continue to be born infected despite the pregnant woman's access to prenatal care, the availability of diagnostic tests, and the effectiveness of the treatment for pregnant woman and the fetus. 26

There was also a significant association between the covariable sex and EUGR, corroborating with other authors. The bivariate analysis showed a higher occurrence of EUGR in females. The final multivariate model also presented a higher risk in females $(\mathrm{RR}=1.50, \mathrm{CI} 95 \%=1.11-2.02)$. Gianini et al.28 also found a lower frequency of EUGR in males, with an odds ratio of $0.39(\mathrm{CI} 95 \%=0.20$ 0.80 ). Some studies state that this difference between sexes, with superior postnatal neonate growth in males, is due to multifactorial causes, among which the best incorporation of muscle mass in boys. 29

According to this study, it showed that neonates with lower GA at birth are also exposed to a higher risk of restriction, with moderate preterm infants presenting a higher risk $(\mathrm{RR}=1.41, \mathrm{CI} 95 \%=1.06$ 1.87) compared to late preterm infants. A published

Figure 2

Extrauterine Growth Restriction. Preterm Born Cohort, 2018, Brazil.

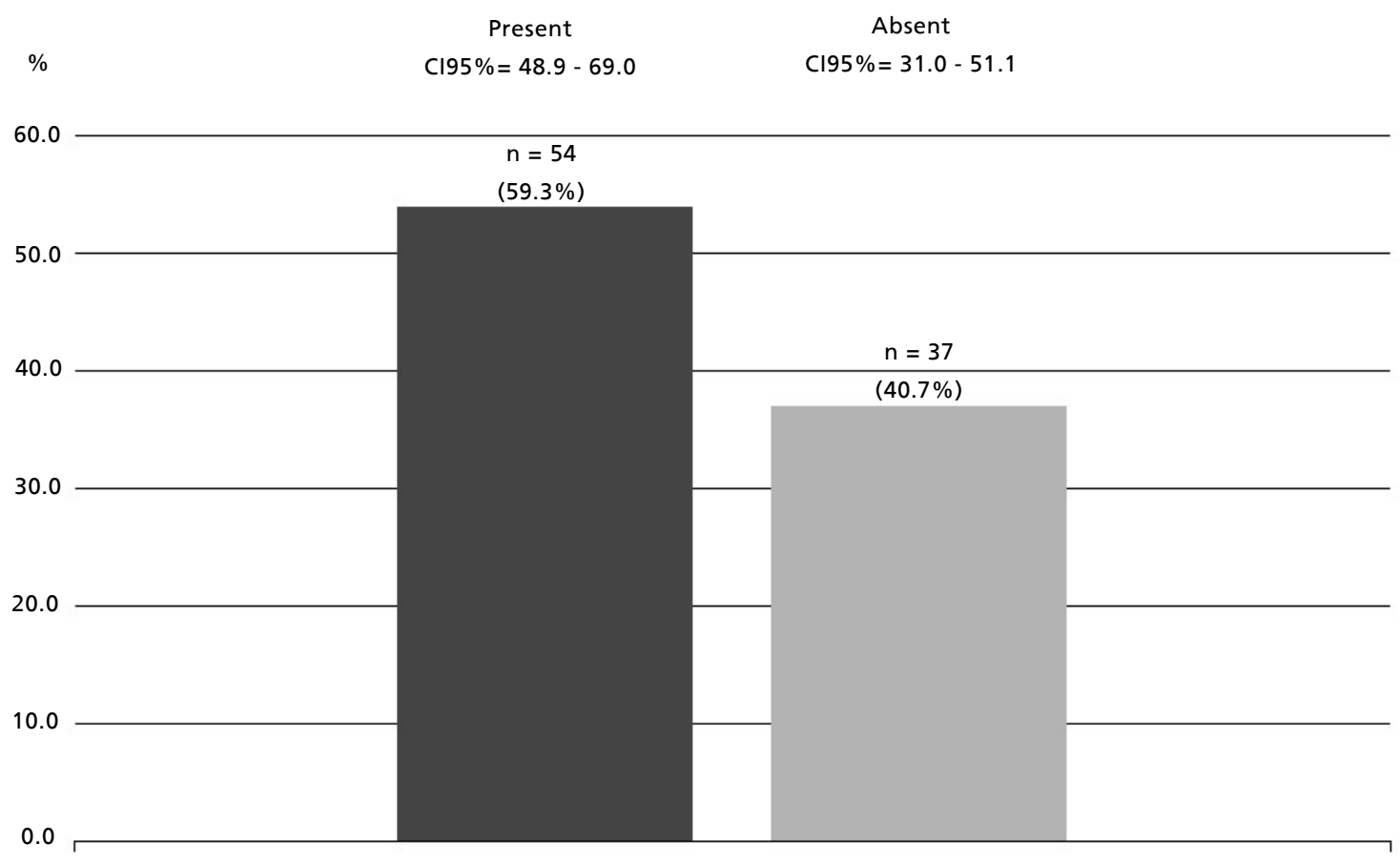

Extrauterine Growth Restriction (EUGR) 
Table 1

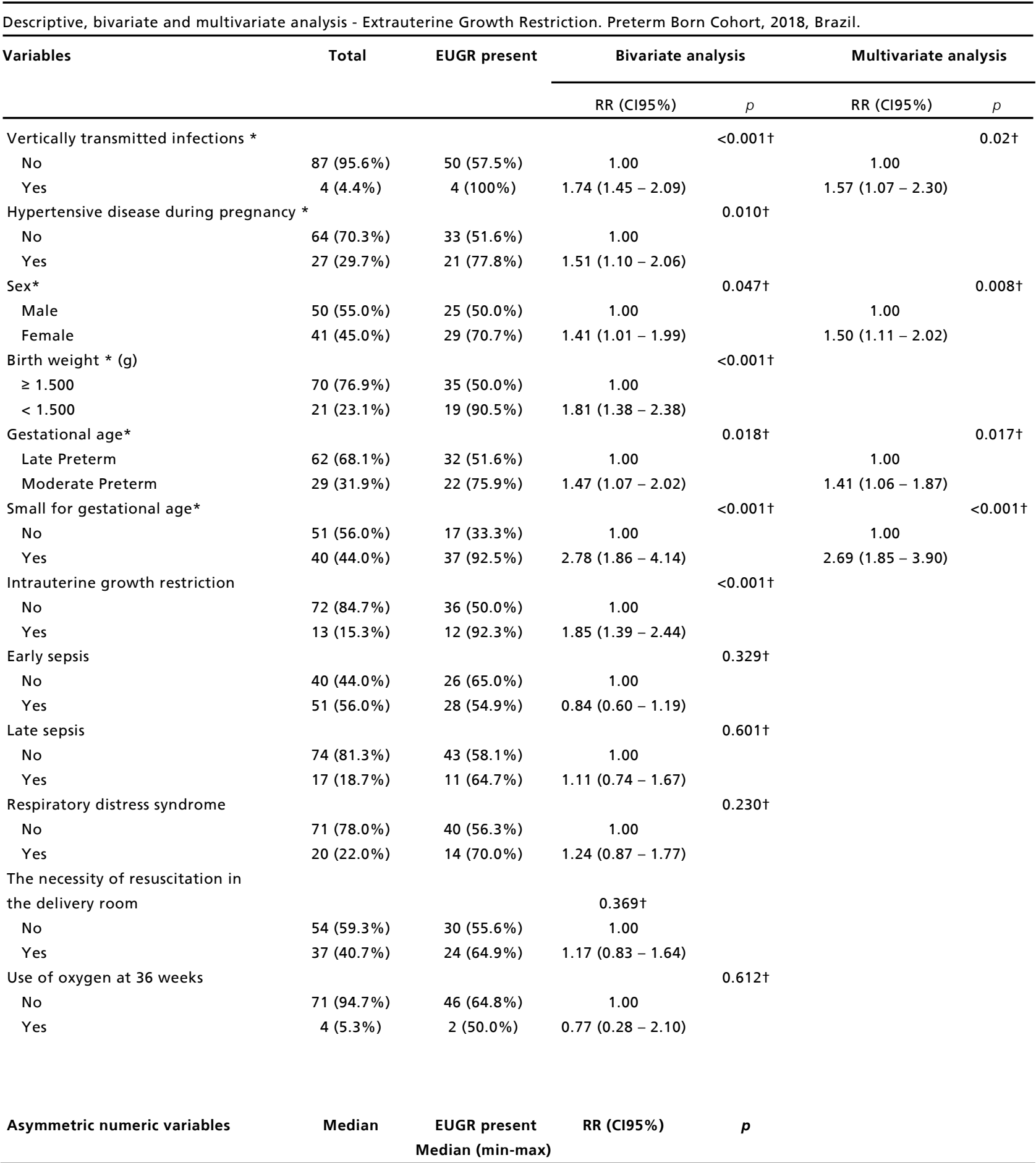

Number of days without enteral

$\begin{array}{lcccc}\text { feeding (in days) } & 1(0-9) & 1(0-7) & 0.99(0.89-1.11) & 0.905 \dagger \\ \text { Time of supplemental } & 4(0-24) & 4(0-23) & 1.00(0.96-1.03) & 0.846 \dagger\end{array}$

Time of supplemental oxygen use

$4(0-24)$

$4(0-23)$

$0.846+$

* Variables used in the adjusted analysis: vertically transmitted infections, hypertensive disease during pregnancy, sex, birth weight, gestational age, small for gestational age.

+ Wald test; $R R=$ relative risk; $C 195 \%=$ confidence interval. 
study by Cao et al. 8 (2015), in China, reported that the incidence of EUGR increased with decreasing GA at birth.

Studies show that preterm neonate born SGA can have an important impact on postnatal growth. Freitas et al. 2 conducted a cross-sectional study in 2016 in Minas Gerais with 254 preterm infants hospitalized in a neonatal unit, and observed that being born SGA increased the chance of EUGR by 6.14 times, with $84 \%$ of preterm SGA presenting restriction. A longitudinal study by Lima et al.7 analyzed a cohort of 570 preterm infants in Rio de Janeiro and reported that the risk factor with the greatest impact was being born SGA, with a 4.33 fold had greater chance of growth restriction at discharge. Our results also demonstrated an important association of this covariate with the EUGR outcome. The SGA classification increased the chance by $2.69(\mathrm{CI} 95 \%=1.85-3.90)$, and $92.5 \%$ of preterm infants born SGA presented EUGR.

This study may have limitations related to a possible information bias due to data collection from medical records. Thus, the analysis of the presence of hypertensive disease during pregnancy, birth characteristics, neonatal morbidities, and clinical practices were prioritized because these data were considered more consistent and reliable. Some

\section{References}

1. Demartini AdA, Bagatin AC, da Silva RPGVC, Boguszewski MCS. Crescimento de crianças nascidas prematuras. Arq Bras Endocrinol Metabol. 2011; 55 (8): 534-40.

2. Freitas BAC, Priore SE, Lima LM, Franceschini SCC. Extrauterine growth restriction: Universal problem among premature infants. Rev Nutr. 2016; 29 (1): 53-64.

3. Embleton NE, Pang N, Cooke RJ. Postnatal malnutrition and growth retardation: an inevitable consequence of current recommendations in preterm infants? Pediatrics. 2001. 107 (2): 270-3.

4. Euser MA, De Wit CC, Finken MJJ, Rijken M, Wit JM. Growth of preterm born children. Horm Res. 2008.; 70 (6): 319-28.

5. Oliveira AG, Siqueira PP, de Abreu LC. Cuidados nutricionais no recém-nascido de muito baixo peso. J Hum Growth Dev. 2008; 18 (2): 148-54.

6. Calkins K, Devaskar SU. Fetal origins of adult disease. Curr Probl Pediatr Adolesc Health Care. 2011; 41 (6): 15876.

7. Lima PAT, Carvalho M, da Costa ACC, Moreira MEL Variables associated with extra uterine growth restriction in very low birth weight infants. J Pediatr. 2014; 90 (1): 22-7. medical records were not found, as they were physical and long-term documents, which made the access and storage in hospital units more difficult.

The causes related to EUGR are complex and multifactorial. This study showed that VTI is an important morbidity factor with relevant impact on the growth of preterm infants. VTI diseases can be prevented or have their consequences minimized by optimized family planning, prenatal and neonatal care. Thus, intervention actions can reduce several sequelae, including the incidence of EUGR. In view of the findings of this study, further studies are necessary to continue investigating the impact of VTI on the occurrence of EUGR in NICU.

\section{Authors' contribution}

Study conception and design: Vieira VC, Lima RG and Medeiros DS. Data collection: Vieira VC, Lima RG and Queiroz DB. Statistical analysis and interpretation: Vieira VC and Medeiros DS. Drafting: Vieira VC. Critical review: Lima RG and Queiroz DB. All authors approved the final version of the article.

8. Cao W, Zhang YH, Zhao DY, Xia HP, Zhu TW, Xie LJ. Risk factors for extrauterine growth restriction in preterm infants with gestational age less than 34 weeks. Chinese J Contemporary Pediatrics. 2015; 17 (5): 453-8. Disponível em: https://europepmc.org/article/med/26014694

9. Freitas BAC, Sant'Ana LFR, Barros J, Priore SL, Barros JFN, Fraceschini SCC. Crescimento do prematuro: revisão sobre as curvas de referência. Rev Pediatr SOPERJ. 2012; 13: 4-15.

10. Ehrenkranz RA. Extrauterine growth restriction: is it preventable? J Pediatr. 2014; 90 (1): 1-3.

11. Guia prático: infecções no ciclo grávido-puerperal. In: Fernandes CE, De Sá MFS, editors. Orientações e Recomendações. FEBRASGO. 2. São Paulo. [periódico online] 2016; p. 92. Disponível em: https://www.febrasgo.org.br/media/k2/attachments/02INFECCOyES_NO_CICLO_GRAVIDO_PUERPERAL.pd $\mathrm{f}$

12. Madrid L, Varo R, Sitoe A, Bassat Q. Congenital and perinatally-acquired infections in resource-constrained settings. Expert review of anti-infective therapy. [periódico online] 2016 [acesso em 20 fev 2020];14(9):845-61. Disponível em: https://www.ncbi.nlm.nih.gov/pubmed/27442227 
13. Waldorf KMA, McAdams RM. Influence of infection during pregnancy on fetal development. Reproduction. 2013; 146 (5): R151-R62.

14. Brasil. Ministério da Saúde. Secretaria de Atenção à Saúde. Cadernos de Atenção Básica. Atenção ao Pré-Natal de Baixo Risco. In: Saúde. MS, editor. Brasília, DF; [publicação online]. 2012 [acesso em 12 abri 2020]. p. 318. Disponível em: http://bvsms.saude.gov.br/bvs/publicacoes/cadernos_atencao_basica_32_prenatal.pdf

15. São Pedro SAP, da Silva CAL, Rebouças MC, Costa MdFD. Triagem pré-natal de infecções nas macrorregiões sul e sudoeste do estado da Bahia, Brasil: detectadas em papel de filtro. Rev Bras Saúde Mater Infant. 2019; 19 (3): 691-700.

16. Lansky S, Friche AAdL, Da Silva AAM, Campos D, Bittencourt SDdA, De Carvalho ML, De Frias PG, Cavalcante RS, Da Cunha AJLA. Pesquisa Nascer no Brasil: perfil da mortalidade neonatal e avaliação da assistência à gestante e ao recém-nascido. Cad Saúde Pública. 2014; 30: S192-S207.

17. SBP (Sociedade Brasileira de Pediatria). Monitoramento do crescimento de RN pré-termos. In: Neonatologia DCd, editor Sociedade Brasileira de Pediatria [publicação online]. 2017 [acesso em 25 mai 2019]; p. 1-7. Disponível em:

sbp.com.br/fileadmin/user_upload/2017/03/NeonatologiaMonitoramento-do-cresc-do-RN-pt-270117.pdf

18. AAP (American Academy of Pediatrics). Committee on Fetus and Newborn and ACOG Committee on Obstetric Practice. Guidelines for Perinatal Care, 8th Edition. editors Kilpatrick SJ, Papile L-A, Macones GA, [livro online] 2017 [acesso em 12 abri 2020]. 710 p. Disponível em: https://reader.aappublications.org/guidelines-for-perinatalcare-8th-edition/3

19. Gordijn S, Beune IM, Thilaganathan B, Papageorghiou A, Baschat AA, Baker PN, Silver RM, et al. Consensus definition of fetal growth restriction: a Delphi procedure. Ultrasound Obstet Gynecol. 2016; 48 (3): 333-9.

20. Montserrat IRM, Aldecoa-Bilbao V, Balcells Esponera C, del Rey Hurtado de Mendoza B, Iriondo Sanz M, IglesiasPlatas I. Applying Methods for Postnatal Growth Assessment in the Clinical Setting: Evaluation in a Longitudinal Cohort of Very Preterm Infants. Nutrients. 2019; 11 (11): 2772.

21. Shah PS, Wong KY, Merko S, Bishara R, Dunn M, Asztalos E, Darling PB. Postnatal growth failure in preterm infants ascertainment and relation to long-term outcome. J Perinatal Med. 2006; 34 (6): 484-9.

\section{Received on May 8, 2020}

Final version presented on October 27, 2020

Approved on December 28, 2020
22. Villar J, Giuliani F, Barros F, Roggero P, Coronado Zarco IA, Rego MAS, Ochieng R, Gianni ML, Rao S, Lambert A, Ryumina I, Britto C, Chawla D, Ismail LC, Ali SR, Hirst J, Teji JS, Abawi K, Asibey J, Duah JA, McCormick K, Bertino E, Papageorghiou AT, Figueras JA, Bhutta Z, Kennedy S. Monitoring the postnatal growth of preterm infants: a paradigm change. Pediatrics. 2018; 141 (2): e20172467.

23. Clark RH, Thomas P, Peabody J. Extrauterine growth restriction remains a serious problem in prematurely born neonates. Pediatrics. 2003; 111 (5): 986-90.

24. Cooke R, Foulder-Hughes L. Growth impairment in the very preterm and cognitive and motor performance at 7 years. Arch Dis Childhood. 2003; 88 (6): 482-7.

25. Costa GB, de Oliveira MC, Gadelha SR, Albuquerque GR, Teixeira M, Raiol MRdS, Sousa SMB, Marin LJ. Infectious diseases during pregnancy in Brazil: seroprevalence and risk factors. J Infect Dev Countr. 2018; 12 (08): 657-65.

26. Castro Romanelli RM, Carellos EVM, Campos FA, de Paula Pinto AS, Marques BA, Anchieta LM, Andrade GMQ. Abordagem neonatal nas infecções congênitas-toxoplasmose e sífilis. Rev Méd Minas Gerais. 2014; 24 (2) 202-15.

27. Brasil. Ministério da Saúde.Secretaria de Vigilância em Saúde. Departamento de DST, Aids, e Hepatites Virais. Caderno de boas práticas: o uso da penicilina na atenção básica para a prevenção da sífilis congênita no Brasil. Brasília, DF; 2015 [acesso em 3 mai 2020]. Disponível em: http://bvsms.saude.gov.br/bvs/publicacoes/penicilina_para prevencao sifilis congenita $\% 20$ brasil.pdf

28. Gianini NM, Vieira AA, Moreira MEL. Evaluation of the nutritional status at 40 weeks corrected gestational age in a cohort of very low birth weight infants. J Pediatr. 2005; 81 (1): $34-40$

29. Saigal S, Stoskopf BL, Streiner DL, Burrows E. Physical growth and current health status of infants who were of extremely low birth weight and controls at adolescence. Pediatrics. 2001; 108 (2): 407-15. 